\title{
ANÁLISE DA DÉCADA DA EDUCAÇÃO PARA O DESENVOLVIMENTO SUSTENTÁVEL (DEDS) DA UNESCO A PARTIR DA LEITURA DA PEDAGOGIA DA AUTONOMIA DE PAULO FREIRE
}

Rafaella Sampaio Uchoa ${ }^{1}$

Resumo: Esta pesquisa discute as concepções de sustentabilidade e as propostas pedagógicas da Década da Educação para o Desenvolvimento Sustentável (DEDS) da UNESCO (Organização das Nações Unidas para a Educação, a Ciência e a Cultura) sob a ótica da educação em Paulo Freire. Através de uma análise do documento que fundamenta a DEDS, especificamente o Plano Internacional de Implementação, publicado em 2005, procurou-se identificar categorias em Paulo Freire; mais precisamente, de sua obra Pedagogia da Autonomia, que sustentam as contribuições de suas ideias para uma educação ambiental crítica transformadora e emancipatória; a partir da metodologia de Análise Documental.

Palavras-chave: Educação Ambiental; Paulo Freire; Década da Educação para o Desenvolvimento Sustentável; Educação para o Desenvolvimento Sustentável. 


\section{Introdução}

O documento Plano Internacional de Implementação da DEDS da UNESCO contém os as principais perspectivas da DEDS. Neste recorte, procuramos identificar como as concepções de sustentabilidade e as perspectivas pedagógicas presentes no documento se distanciam de uma Educação Ambiental libertária e emancipatória, pensada a partir de Paulo Freire. Alguns conceitos e perspectivas de Paulo Freire foram utilizados como categorias de análise do documento, através da metodologia de Análise de Conteúdo segundo Bardin, em especificamente Análise Documental.

A Análise Documental é considerada uma interpretação ou ressignificação do conteúdo original de um documento, atribuída pela leitura crítica do pesquisador (BARDIN, 2011). A pesquisa partiu de questionamentos que embasaram o estudo: a EDS presente no discurso da UNESCO defende que tipo de educação no termo "educação para o desenvolvimento sustentável" em quais propostas pedagógicas? Este e outros questionamentos foram acompanhados pela leitura de A Pedagogia da Autonomia, de Paulo Freire, que nos traz a conceituação de uma educação libertária e emancipatória, entendida como uma educação capaz de construir uma consciência das condições de opressão entre opressores e oprimidos, capaz de desvelar os caminhos possíveis para que os sujeitos se libertem destas condições.

Procurou-se tecer diálogos com o campo da Educação Ambiental Crítica, a fim de embasar uma reflexão acerca dos aportes teóricos para esta abordagem, intencionando ampliar o debate da própria perspectiva crítica. Uma vez que, segundo Loureiro (2005, p.15), esta é compreendida como "práxis educativa e social que tem por finalidade a construção de valores, conceitos, habilidades e atitudes que possibilitem o entendimento da realidade de vida e a atuação lúcida e responsável de atores sociais individuais e coletivos no ambiente (...)".

\section{A Educação para o Desenvolvimento Sustentável da UNESCO}

A ideia de "desenvolvimento sustentável" (DS) surge a partir do relatório Brundtland, em 1987. O documento trouxe ao mundo pela primeira vez o conceito de 'desenvolvimento sustentável', definido como "desenvolvimento que atende às necessidades do presente sem comprometer a possibilidade de as gerações futuras atenderem suas necessidades" (UNESCO, 1987. p.20)

A ideia da cooperação entre as nações e a necessidade de diplomacia política é muito presente desde a Conferência de Estocolmo, em 1972, sendo associada a todos os encontros internacionais de Educação Ambiental da ONU (Organização das Nações Unidas).

A discussão sobre o desenvolvimento sustentável, no âmbito da UNESCO, começa então a se situar em seus documentos, orientando políticas e apontando diretrizes estratégicas para a implementação das propostas coerentes com o conceito de desenvolvimento sustentável. Podemos observar 
que esta concepção procura promover a criação de políticas que articulem as dimensões social, econômica e ambiental. Para a instituição; "soluções tecnológicas, regulação política e instrumentos financeiros, isolados, não são suficientes para transformar modos de pensar e de agir" (UNESCO, 2005: p.10).

Dessa forma, a educação sendo situada como uma dimensão pragmática e uma ação que vai promover o "desenvolvimento sustentável", identificamos as premissas deste projeto como estruturante de uma perspectiva de educação que se compromete com eixos propulsores de uma ideia força: o desenvolvimento sustentável.

\section{A Educação para o Desenvolvimento Sustentável sob uma leitura da Pedagogia da Autonomia de Paulo Freire}

Quando pensamos em Paulo Freire, há de se reconhecer sua enorme importância para o universo educativo. Analisando o documento da DEDS com o propósito de pensar uma "educação para o desenvolvimento sustentável" disposta a ir além de pragmatismos; as contribuições de Paulo Freire se fazem urgentes. Em uma obra dedicada a buscar estas linhas de aproximação, Layrargues (2014), percebe um equilíbrio de forças:

Paulo Freire nos brinda com uma fórmula possível de lidar e transformar a realidade presente no mundo. A leitura e compreensão do mundo em Paulo Freire é a possibilidade de tomar o destino nas próprias mãos. É a possibilidade de se construir outro projeto societário, por meio da Educação. (...) Uma coisa é certa: Paulo Freire está presente na educação ambiental (LAYRARGUES, 2014, p. 10).

Layrargues (2014, p.7) traz à tona a importância que Paulo Freire representa para este campo social, sugerindo que o pensamento freireano seja capaz de oferecer possibilidades de "enfrentamento e superação das formas de opressão, controle e poder autoritário".

A necessidade do diálogo entre a perspectiva central do documento analisado e as perspectiva freireana se faz ainda mais urgente à medida que as partes envolvidas se distanciam uma da outra; trilhando um caminho que contemple uma educação problematizadora. Segundo o próprio autor,

Devo deixar claro que, embora seja meu interesse central considerar neste texto saberes que me parecem indispensáveis à prática docente de educadoras ou educadores críticos, progressistas, alguns deles são igualmente necessários a educadores conservadores. São saberes demandados pela prática educativa em si mesma, qualquer que seja a opção política do educador ou educadora (FREIRE, 2006, p.21) 


\section{O "espírito crítico" da EDS e a criticidade em Paulo Freire}

Os conceitos e abordagens que orbitam em torno da educação, no documento da DEDS, são muitos. Existe uma apropriação de um discurso e de termos que são colocados como críticos. Um trecho da Sessão I denota esta perspectiva:

A EDS promove os mesmos saberes, bem como o desejo de continuar aprendendo, de cultivar o espírito crítico, de trabalhar em grupo e de procurar e aplicar os conhecimentos. Desta maneira, os educandos estarão bem mais equipados para tomar decisões que levem ao desenvolvimento sustentável (UNESCO, 2005, p.45).

A criticidade aparece também no Resumo Executivo do documento, quando, entre outras coisas, coloca que:

A EDS reflete a preocupação por uma educação de alta qualidade e apresenta as seguintes características: (...) desenvolver o pensamento crítico e a capacidade de encontrar solução para os problemas: ensinar a ter confiança ante os dilemas e desafios em relação ao desenvolvimento sustentável (UNESCO, 2005, p. 19).

A proposta de uma dimensão crítica na EDS, além de não ser fundamentada epistemologicamente, é anulada por uma dimensão que se contrapõe a uma educação em perspectiva crítica, em passagens do texto que, apesar de sugerirem uma educação transformadora, não problematizam suas próprias premissas. Em um momento da Sessão I ("EDS: Promover Valores"), um trecho é destacado em caixa de texto com o seguinte título: "Papéis-chave para a educação" e itemizado nas seguintes definições: "A educação deve inspirar a crença que cada um de nós tem o poder e a responsabilidade de introduzir mudanças positivas em escala global"; "A educação é o principal agente de transformação para o desenvolvimento sustentável, aumentando a capacidade das pessoas de transformarem sua visão de sociedade em realidade"; "A educação incentiva os valores, comportamento e estilos de vida necessários para um futuro sustentável"; "A educação fortalece a capacidade de reflexão orientada para o futuro".

A educação por si mesma é parte de um sistema econômico mais amplo e é influenciada pelos padrões de oferta e demanda, pelos níveis de taxação e por outras forças econômicas, que também funcionam como reguladoras do meio ambiente. Para que a EDS encontre seu caminho nas ofertas educacionais que respondam às forças do mercado, torna-se importante influenciar as normas e o funcionamento do mercado (UNESCO, 2005, p.56). 
O posicionamento crítico da EDS não se dispõe em questionar esta mercantilização da educação naturaliza este processo, considerando fundamental achar seu espaço nas chamadas ofertas educacionais do mercado educativo. Paulo Freire contribui na análise deste trecho:

A ideologia fatalista, imobilizante, que anima o discurso neoliberal anda solta no mundo. Com ares de pósmodernidade, insiste em convencer-nos de que nada podemos contra a realidade social que, de histórica e cultural, passa a ser ou a virar quase natural (FREIRE, 2006, p.19).

A comparação com esta abordagem freireana se faz no sentido de demonstrar como o discurso da UNESCO acolhe a educação mercantilizada.

No que tange uma correlação entre Paulo Freire e o pensamento crítico, é indispensável colocar o que o autor entendia ser esta educação construída com criticidade. $\mathrm{Na}$ elucidação sobre "saberes demandados para a prática educativa em si mesma, qualquer que seja a opção política do educador ou educando" (FREIRE, 2006, p. 23), destacamos o momento em que Paulo Freire aponta a criticidade como demanda para o ensinar. Partindo disto, amarra a criticidade aos pés da curiosidade, que em se fazer crítica, passa da curiosidade ingênua para a curiosidade epistemológica. Este é um ponto importante a ser tocado: um discurso que se debruça na prática educativa, ausente de construção epistemológica, esvazia o leitor da própria curiosidade epistemológica e consequentemente, não convoca seu potencial indagador.

Documentos com generalizações podem pasteurizar o pensamento, homogeneizando a leitura do mundo, ou podem instigar uma leitura problematizadora da realidade do tempo presente, historicamente construído e, consequentemente, capaz de motivar o educando a questioná-la e transformála. Esta instigação é capaz de fazer emergir uma curiosidade que põe o educando em uma zona de movimento com a habilidade de fazê-lo encontrar seu próprio caminho para a transformação desta realidade problematizada.

Não haveria criatividade sem a curiosidade que nos move e nos põe pacientemente impacientes diante do mundo que não fizemos, acrescentando a ele algo que fazemos. (...) Como manifestação presente à experiência vital, a curiosidade humana vem sendo histórica e socialmente construída e reconstruída. Precisamente porque a promoção da ingenuidade para a criticidade não se dá automaticamente, uma das tarefas precípuas da prática educativo-progressista é exatamente o desenvolvimento da curiosidade crítica, insatisfeita, indócil (FREIRE, 2006, p.32). 
$\mathrm{Na}$ falta de uma elaboração histórica, a proposta da EDS leva a educação e o meio ambiente para o palco, iluminados pelos refletores do senso comum. A EDS pensa um futuro sustentável, dedica seus esforços ao tempo que está por vir, ao Planeta que vamos deixar; apagando a realidade do tempo presente, retirando dos educandos a "experiência social que eles têm como indivíduos" (FREIRE, 2006), no afastamento das realidades concretas. A motivação de uma curiosidade ingênua cabe como uma luva em uma educação cujos objetivos se voltam para um futuro idealizado, descompromissado com as formas de contemplação do presente. Esta questão é mais sobre a problematização e o senso crítico do papel educativo do que o futuro ou o presente propriamente ditos. Segundo Paulo Freire,

A desproblematização do futuro numa compreensão mecanicista da História, de direita ou de esquerda, leva necessariamente à morte ou à negação autoritária do sonho, da utopia, da esperança. E que, na inteligência mecanicista, portanto determinista da História, o futuro é já sabido. A luta por um futuro assim 'a priori' conhecido prescinde da esperança. A desproblematização do futuro, não importa em nome de quê, é uma violenta ruptura com a natureza humana social e historicamente constituindo-se (FREIRE, 2006, p.73).

\section{"Capacitação e Treinamento": transferência de conhecimento?}

Assim como outros termos e grifos presentes no texto do documento da DEDS, este é um dos itens que mais demarcam a perspectiva instrumentalista sobre educação. $O$ uso das palavras capacitar e treinar esvaziam o processo educativo do reconhecimento da identidade cultural do educando, correndo o risco de posicionar o discurso da prática educativa em um espaço autoritário, superior, vertical. O perigo de confundir o 'ensinar' com o 'treinar' ou o 'capacitar' se dá na iminência de meramente transferir conhecimento, depositar conteúdos julgados como melhores, na busca de se alcançar um resultado considerado bom.

$\mathrm{Na}$ busca de evitar um caráter colonizador do pensamento do outro, em um processo que pode se desenvolver em um verdadeiro atropelamento, Paulo Freire convida o "reconhecimento e a assunção da identidade cultural" (FREIRE, 2006, p.42) para a importância no fazer educativo:

Uma das tarefas mais importantes da prática educativo-crítica é propiciar as condições em que os educandos em suas relações uns com os outros e todos com o educador ensaiam a experiência profunda de assumir-se. (...) A questão da identidade cultural, de quem fazem parte a dimensão individual e a de classe dos educandos cujo respeito é absolutamente fundamental na prática educativo-progressista, é problema que 
não pode ser desprezado. É isto que o puro treinamento do professor não faz, perdendo-se e perdendo-o na estreita e pragmática visão do processo. (...) A aprendizagem da assunção do sujeito é incompatível com o treinamento pragmático. (FREIRE, 2006, p.42).

Apesar da presença das palavras "capacitação e treinamento" em um documento que fala de educação, seria um tanto quanto precipitado afirmar, apenas a partir deste emprego, que esta perspectiva é pragmática, rasa, superficial em sua proposta. O uso destas palavras é um indicativo desta visão instrumentalista; mas se faz necessário, para uma conclusão construída, uma análise que se aproxime do conteúdo que se encontra neste rótulo.

A Seção II do documento da DEDS, chamada de "Atores e Estratégias", dedica um espaço específico para colocar sete estratégias como sendo fundamentais no alcance do desenvolvimento sustentável. São elas: promoção e projeção; consulta e apropriação; parcerias e redes; capacitação e treinamento; pesquisa e inovação; uso das tecnologias de informação e comunicação e monitoramento e avaliação. A quarta estratégia - "capacitação e treinamento", é apresentada junto ao cumprimento de "abordagens que fornecem habilidades duradouras que poderiam ser aplicadas na prática" Estas abordagens são chamadas de "áreas-chave" e são itemizadas em:

1) Comunicação e Conscientização;

2) Planejamento, Gestão e Avaliação;

3) Treinamento e Capacitação de Educadores;

4) Instrumentos de análise;

5) Conteúdos e Materiais Didáticos

$\mathrm{O}$ item 3 preconiza que:

No sistema de educação formal e nos contextos não-formais de educação, o nível de conhecimento e entusiasmo do educador torna-se fator-chave na estimulação do interesse dos alunos e no reconhecimento das questões relativas ao desenvolvimento sustentável. As atitudes e métodos que o educador emprega devem refletir os valores do desenvolvimento sustentável, assim como ajustar-se às normas mais elevadas da prática pedagógica (UNESCO, 2005, p.77). 
educação que busque a autonomia e a historicidade dos sujeitos e dos territórios. E com este fim que se propõe uma análise sob contribuições freireanas. Além de rotular e amarrar a educação em reducionismos deste tipo, o trecho ainda se alonga em sugerir que a metodologia e a atitude do educador também se ajustam a normas elevadas da prática pedagógica. Lê-se: uma prática pedagógica marcada com padrões de excelência e com selos de "boa qualidade". O que se entende por sustentabilidade se transforma, assim, em um conteúdo que deve ser ensinado no ajustamento de normas. Paulo Freire distingue formação de treinamento, quando afirma que "formar é muito mais do que puramente treinar o educando no desempenho de destrezas (...) daí a crítica presente em mim à malvadez neoliberal, ao cinismo de sua ideologia fatalista e a sua recusa inflexível ao sonho e à utopia" (FREIRE, 2006, p.14).

\section{A "aquisição de conhecimentos": educação bancária?}

A discussão em torno desta crítica se relaciona em muito com o conceito de educação bancária de Paulo Freire. Não são raros os momentos da DEDS em que são expressados a proposta de transferência de conhecimentos, valores e habilidades necessárias para o cumprimento do desenvolvimento sustentável. No item "Espaços de Aprendizado", que pertence ao espaço reservado para as "Perspectivas", grifa-se trechos como:

As diferentes partes do sistema educacional, incluindo instituições religiosas e oportunidades de aprendizagem fora destes sistemas, desempenham diferentes funções no que diz respeito ao programa EDS, mas seu objetivo é o mesmo capacitar o aprendiz a adotar práticas e comportamentos que incentivem o desenvolvimento sustentável tanto individual como coletivamente (UNESCO, 2005, p.56).

O trecho continua relacionando a penetração das perspectivas da EDS nos segmentos do ensino, trazendo, neste contexto, a "aquisição de conhecimentos":

O programa EDS exige que se reexamine a política educacional, no sentido de reorientar a educação desde o jardim de infância até a universidade e o aprendizado permanente na vida adulta, para que esteja claramente enfocado na aquisição de conhecimentos, competências, perspectivas e valores relacionados com a sustentabilidade. Para isso é necessário revisar os objetivos e conteúdo dos currículos para desenvolver uma compreensão interdisciplinar da sustentabilidade (UNESCO, 2005, p.57). 
Como se pode perceber, esta dimensão fica bem demarcada em vários momentos, representada em diferentes propostas, como a reforma do currículo e de políticas de educação, a interdisciplinaridade, a diversidade participativa através de distintos espaços de aprendizagem e a intenção formativa, que deve passar por todos os segmentos da educação.

A analogia com o conceito de educação bancária de Paulo Freire parte destas análises e busca uma forma de desvelar este discurso. O autor revela esta concepção com o papel das funções narradoras, dissertadoras, no âmbito da prática educativa:

Há uma quase enfermidade da narração. (...) Nela, o educador aparece como seu indiscutível agente, como seu real sujeito, cuja tarefa indeclinável é "encher" os educandos dos conteúdos de sua narração. Conteúdos que são retalhos da realidade desconectados da totalidade em que se engendram e em cuja visão ganhariam significação. (...) Desta maneira, a educação se torna um ato de depositar, em que os educandos são os depositários e o educador, o depositante. (FREIRE, 2006, p.66).

Neste sentido, Paulo Freire identifica a educação bancária como instrumento da opressão, "refletindo a sociedade opressora, sendo dimensão da 'cultura do silêncio', que mantém e estimula a contradição". Este silenciamento se relaciona com o que se entende pela 'opressão ambiental', gerando 'oprimidos ambientais', na dimensão ambiental da ideia de opressão elaborada por Paulo Freire.

\section{O conceito de Oprimido Ambiental}

Paulo Freire pensa uma pedagogia do oprimido que revela a existência de uma relação entre opressores e oprimidos, onde tal educação seria capaz de libertar o sujeito de sua condição de oprimido; sendo, portanto considerada uma educação libertária e emancipatória, permitindo a tomada de consciência de sua condição de sujeito histórico, que o permite reconhecer-se como sujeito no mundo, percebendo sua dimensão histórica e social. Paulo Freire entendeu que esta condição de opressão é socialmente elaborada.

$\mathrm{Na}$ compreensão destas ideias centrais em Paulo Freire, que desenvolvem uma ontologia na percepção de como este sujeito se constitui em seu processo de tomada de consciência e como se constitui como ser humano; o conceito de oprimido ambiental contempla a tomada de consciência do sujeito acerca das condições ambientais nas quais ele está imerso. Nós, cidadãos do mundo, nas condições impostas por nosso sistema econômico, somos obrigados, por exemplo a seguir padrões de alimentação, moradia, acesso à água, ao ar e ao território. Acessos estes que passaram a ser controlados pelo capital, que foram privatizados em função de uma ordem Revbea, São Paulo, V. 13, № 2: 340-350, 2018. 
econômica escravizadora da liberdade e do direito do sujeito ao livre acesso a estes elementos, constituintes de seu acesso à vida propriamente dita.

No conceito de oprimido ambiental, cabem as populações tanto ricas, como pobres: a própria "compra" de um ar mais limpo, representada pela moradia em regiões mais caras em grandes cidades, por exemplo; ou a alimentação encharcada de agrotóxicos, que atinge todas as classes sociais, ou a falta de saneamento básico, que assola diversas populações, são relações que oprimem o sujeito ambientalmente. Não se trata aqui de seu poder aquisitivo propriamente dito, capaz de fornecer uma melhor ou pior qualidade de vida. Trata-se da imposição que o capitalismo impõe ao ser humano na restrição de seu bem comum: os espaços e recursos naturais.

É relevante trazer para esta reflexão uma comparação com o discurso da Unesco sobre a prática pedagógica que gira em torno da EDS: um discurso que estivesse disposto a

superar a contradição, já não seria bancário. Já não faria depósitos. Já não tentaria domesticar. Já não prescreveria. Saber com os educandos, enquanto estes soubessem com ele, seria sua tarefa. Já não estaria a serviço da desumanização. A serviço da opressão, mas a serviço da libertação (FREIRE, 2006, p.71).

A não ruptura do documento da DEDS com estas contradições e com a intenção de treinamento, capacitação e aquisição de conhecimentos, em uma perspectiva de educação utilitarista e desproblematizada, no alcance do chamado desenvolvimento sustentável; o coloca em um lugar de opressor, em uma motivação velada de "transformar a mentalidade dos oprimidos e não a situação que os oprime" (FREIRE, 2006, p.71).

\section{Considerações Finais}

Ao trazer as concepções sobre educação e sustentabilidade no âmbito da UNESCO, nossos esforços se concentram em desvelar a expectativa de educadores, que corre o risco de ser ingênua quanto à atuação da UNESCO, principalmente no que se refere à incorporação dos discursos presentes na proposta de Educação para o Desenvolvimento Sustentável. Neste sentido, este trabalho não sugere que estes discursos sejam por completo ignorados, dada a realidade de seu forte impacto no âmbito educativo, mas que sejam questionados e utilizados de uma forma que não violente as realidades, conflitos e problemas locais, no que diz respeito às práticas educativas.

A análise de trechos do documento da DEDS através de conceitos de Paulo Freire representa uma alternativa para perspectivas da Educação Ambiental Crítica e neste trabalho em específico, nos coloca em um lugar que nos possibilita visualizar os caminhos possíveis de se romper com uma 
educação colonizadora e consensual. Aqui, Paulo Freire é indispensável na busca de tentativas que denunciam a ausência de uma proposta educativa problematizadora no documento analisado da DEDS. Esta invisibilidade aparece, por exemplo, na proposta utilitarista que embasa o Programa de Educação para o Desenvolvimento Sustentável, identificada nas análises do documento.

Diante destas percepções, sugere-se que o documento não dá conta de discutir (não responde) as problemáticas e discussões que constituem a crise ambiental, no apagamento da dimensão histórica dos problemas ambientais, na proposição de uma educação que se afasta de seu próprio compromisso crítico na construção e no exercício da cidadania. Isto aparece na forma de um discurso que pode ser interpretado como instrumentalista, representado no cumprimento de metas e agendas.

Diante disto, a partir das perspectivas da Educação Ambiental Crítica, sugere-se que, partindo de Paulo Freire, é possível buscar caminhos de pedagogizar a crise ambiental que se constitui em condições de opressão e que demanda uma educação construída nos princípios da autonomia e da libertação destas condições opressoras.

\section{Referências}

FREIRE, P. Pedagogia do Oprimido, São Paulo: Paz e Terra, 2006

FREIRE, $P$. Pedagogia da Autonomia: saberes necessários à prática educativa. São Paulo: Paz e Terra, 1996.

LAYRARGUES, P.P. A dimensão freireana na Educação Ambiental. In: LOUREIRO, C.F.B.; TORRES, J.R., Educação Ambiental: dialogando com Paulo Freire, São Paulo: Cortez, 2014

LOUREIRO, C.F.B. Educação Ambiental e Movimentos Sociais na Construção da Cidadania Ecológica e Planetária. In: LOUREIRO, C.F.B; LAYRARGUES, P.P.; CASTRO, R.S. (orgs.) Educação Ambiental: repensando o espaço da cidadania. São Paulo: Cortez, 2005.

UNESCO. Década das Nações Unidas da Educação para o Desenvolvimento Sustentável: Documento Final/Plano Internacional de Implementação. Brasília, Unesco, 2005. 